

\title{
ANÁLISE DA IMPLEMENTAÇÃO DA POLÍTICA DE COMPRAS PÚBLICAS SUSTENTÁVEIS: um estudo de caso
}

\author{
Vitor Neves Cabral 1 \\ Biancca Scarpeline de Castro ${ }^{2}$
}

\section{Resumo}

Enquanto grande consumidor, o Estado identificou sua capacidade de contribuir com o equilíbrio ambiental, a justiça social e com a economia de recursos públicos por meio da política de compras sustentáveis. No entanto, verifica-se que as políticas públicas, inclusive aquelas relacionadas às compras governamentais, muitas vezes não são implementadas conforme planejadas. Nesse sentido, este trabalho buscou apresentar os resultados da análise de implementação da política de compras sustentáveis em uma instituição federal de ensino (CEFET/RJ) para compreender os desafios para a implementação desta política. Para isso, realizou pesquisas bibliográficas, análise de documentos e entrevistas com funcionários da instituição investigada. Os resultados mostram um baixo compromisso e falta de capacidade da organização analisada para implementação da política pública de compras sustentáveis.

Palavras-Chave: Compras sustentáveis, Implementação de política pública.

\section{ANALYSIS OF THE IMPLEMENTATION OF SUSTAINABLE PUBLIC PROCUREMENT POLICY: a case study}

\begin{abstract}
As a major consumer, the State has identified its ability to contribute to environmental balance, social justice and the economy of public resources through its sustainable purchasing policy. However, frequently check public policies, including those related to solicited purchases, often not implemented as planned. In this sense, this paper aimed to present the results of the analysis of sustainable purchasing policies in a federal educational institution (CEFET/RJ) to understand the challenges to implement this policy. For this, we conducted bibliographic research, document analysis and interviews with employees of the investigated institution. The results show a low commitment and lack of capacity of the analyzed organization to implement sustainable purchasing public policy.
\end{abstract}

Keywords: Sustainable procurement. Public policy. implementation.

Artigo recebido em: 13/09/2019 Aprovado em: 23/04/2020

DOI: http://dx.doi.org/10.18764/2178-2865.v24n1p49-67.

\footnotetext{
${ }^{1}$ Administrador. Mestre em Administração pela Universidade Federal Rural do Rio de Janeiro (UFRRJ). Administrador do Centro Federal de Educação Tecnológica Celso Suckow da Fonseca (CEFET/RJ) - Unidade Itaguaí. Endereço do Vínculo: Rodovia Mário Covas, Lote J2, Quadra J, s/n, Distrito Industrial, Itaguaí - RJ. CEP 23812-101. Email: vitornevescabral@hotmail.com.

2 Economista. Doutora em Ciências Sociais pela Universidade Estadual de Campinas (UNICAMP). Professora Adjunta da Universidade Federal Rural do Rio de Janeiro (UFRRJ) e do Programa de Mestrado Profissional em Gestão e Estratégia (PPGE) da UFRRJ. Endereço: Rodovia BR 465, Km 07, s/n, Zona Rural, Seropédica - RJ. CEP 23890-000. Email: bianccastro2@gmail.com.
} 


\section{INTRODUÇÃO}

Em 1972, a Organização das Nações Unidas (ONU) realizou na cidade de Estocolmo a primeira grande conferência mundial a fim de discutir questões ambientais. Na ocasião foi constatado que a sociedade industrial estava ultrapassando os limites ecológicos globais aceitáveis (ONU, 1972). Como desdobramento desta e de outras reuniões de nível mundial, foi fechada uma série de acordos internacionais em que muitos países se comprometeram com o desenvolvimento sustentável1.

Mais tarde, em 2015, os 193 Estados-Membros da Organização das Nações Unidas adotaram a Agenda 2030, formada por 17 objetivos e 169 metas que direcionam os países na adoção de ações em benefício do desenvolvimento sustentável do planeta até 2030. Dentre os 17 Objetivos para o Desenvolvimento Sustentável (ODS), o de número 12 busca assegurar padrões de produção e consumo sustentáveis, sendo que a sua meta 12.7 almeja a promoção das compras públicas sustentáveis, de acordo com as políticas e prioridades nacionais.

No Brasil as compras públicas representam entre 10\% e 15\% do PIB do país (MMA, 2009; RIBEIRO; INÁCIO JÚNIOR, 2014), o que evidencia o seu impacto na economia e sua capacidade de estimular as cadeias produtivas de materiais e serviços. Assim, a exigência legal de tornar as compras públicas sustentáveis dentro da administração pública direta e indireta é uma política pública que pode ter resultados positivos em direção de uma sociedade que valorize a economicidade, a justiça social e a preservação ambiental.

No entanto, não é raro observar que algumas políticas públicas apresentam resultados divergentes quando comparados aos seus objetivos iniciais, e muitas vezes as razões desse fenômeno podem ser compreendidas a partir do estudo do processo de sua implementação (NEEP, 1999). As compras públicas sustentáveis, por exemplo, conforme consta em relatório do Tribunal de Contas da União, vêm apresentando resultados ínfimos, não alcançando $1 \%$ do total das compras da Administração Pública Federal (TCU, 2018).

Por essa razão, o objetivo desta pesquisa foi analisar o processo de implementação da política de compras públicas sustentáveis no Centro Federal de Educação Tecnológica Celso Suckow da Fonseca (CEFET/RJ) com vistas a identificar os desafios para o pleno atendimento da política. Para isso, foi utilizada a proposição teórica da Matriz $5 \mathrm{C}$, que consiste na identificação e análise de um conjunto de variáveis críticas e interligadas, a fim de obter uma melhor compreensão do processo de implementação de políticas públicas (NAJAM, 1995).

Além desta introdução, o artigo conta com mais quatro seções. Na segunda, será discutida, teoricamente, a implementação das políticas públicas, com foco no desenvolvimento teórico da matriz $5 \mathrm{C}$ de Najam. Na terceira seção será apresentada a metodologia utilizada para realizar a 
pesquisa. Na quarta seção serão discutidos os resultados e na última seção serão apresentadas as considerações finais.

\section{IMPLEMENTAÇÃO DE POLÍTICA PÚBLICA E A MATRIZ 5C}

A implementação de políticas públicas pode ser entendida como o emprego de esforços, conhecimentos e recursos para traduzir as decisões políticas em ação (HOWLETT et al., 2013). Desta forma, a implementação se refere à execução de atividades com vistas ao alcance das metas definidas no processo de formulação das políticas (NEPP, 1999).

A análise da implementação está calcada na literatura que compreende a política pública como um processo composto por fases, formando o ciclo de políticas públicas. Diferentes autores analisam as políticas públicas a partir desse referencial, e possuem em comum o estabelecimento das fases de formulação, implementação e avaliação da política (FREY, 2000). Como fenômeno social, sabe-se que as políticas públicas não possuem fases necessariamente sequenciais, e não representam imperiosamente um processo que possui um começo, meio e fim. Mas, como objeto de pesquisa, a ideia do ciclo de políticas públicas visa simplificar um processo complexo e que se retroalimenta, com a implementação sendo a fase que sucede aquelas que compõem o processo de formulação e antecede as avaliações. Essas últimas são constituídas como processos de aprendizados, para reformular a política com vistas a atender seus objetivos.

Faria (2012) defende o estudo da implementação de políticas públicas pelas seguintes razões: (1) o processo de implementação muitas vezes é o responsável pela frustração dos decisores eleitos com o propósito de solucionar problemas; (2) a política não se traduz em resultados bem sucedidos pela simples disposição de autoridade ou mobilização de recursos; (3) a necessidade de monitorar o comportamento dos agentes mobilizados para a implementação, (4) a importância da produção de informações necessárias ao sucesso de políticas futuras; (5) melhor compreensão do funcionamento da máquina pública.

Durante muito tempo a análise da implementação de políticas públicas pautou-se pela dicotomia entre a perspectiva top-down versus botton up. Na perspectiva top-down, a formulação da política pública é de responsabilidade dos agentes políticos, cabendo aos agentes administrativos a sua execução. A execução da política realizada pelos agentes administrativos refere-se aos aspectos operacionais que deveriam manter-se fiéis às determinações previamente estabelecidas no momento da formulação, não se admitindo qualquer desvio de rota por parte dos implementadores. Os defensores do modelo top-down acreditavam que uma política deveria ser implementada estritamente 
da forma que fora planejada. Tal modelo sugere que o sucesso de uma política pública está em sua adequada formulação, e que a implementação é um processo passivo, que seria bem-sucedido na medida que a política fosse bem planejada. Ou seja, se a implementação é uma consequência, a explicação para o seu sucesso ou fracasso estaria no processo que lhe deu origem. Com isso, o foco principal da análise seria a formulação (LIMA; D'ASCENZI, 2013).

No início da década de 1980, diferentes estudos buscaram compreender as causas da disparidade entre planejamento e implementação das políticas públicas. Surge, portanto,o modelo paradigmático denominado de bottom-up. Neste modelo são enfatizados os elementos presentes no contexto da ação que envolve a implementação da política pública, tomando como variáveis as condições locais e as burocracias (LIMA; D'ASCENZI, 2013). Alguns dos estudos realizados nessa direção foram elaborados por Lipsky (1980), que concluiu que o sucesso ou o fracasso das políticas públicas dependiam do nível de engajamento e das habilidades dos agentes que estariam diretamente envolvidos com a sua implementação. Para Lipsky (1980) tais agentes, denominados de street-levelbureaucracy (burocratas de nível de rua) são os responsáveis pela quantidade e qualidade de serviço público oferecido aos beneficiários (LOTTA, 2012).

Ao abordar a discricionariedade do agente implementador, Lipsky (1980) refere-se à liberdade e autonomia que tais agentes possuem durante a implementação das políticas públicas. Isto significa dizer que, apesar das dimensões políticas oficiais moldarem alguns padrões de decisão, normas comunitárias e administrativas, esses agentes ainda possuem autonomia na decisão de como aplicá-las e inseri-las nas práticas da implementação (LOTTA, 2012). Sabe-se que existe um esforço por parte das organizações para estabelecer por meio de normas um comportamento previsível dos agentes públicos que vão atuar na implementação da política pública, como preconizam as teorias as teorias agente-principal, que buscam oferecer premiações e punições para os agentes que seguem as determinações estabelecidas pelos principais (EISENHARDT, 1989). Contudo, esse esforço não é capaz de eliminar a discricionariedade destes agentes, que estará presente, em alguma medida, durante a implementação.

Lotta (2012) relata que a discricionariedade, presente nas burocracias de nível de rua, pode estar relacionada a um conjunto de regras insuficientes ou ambíguas, ou ao espaço necessário de decisões cotidianas a que os agentes implementadores possuem acesso. Vale lembrar ainda que podem existir ocasiões que não foram previstas no momento da formulação da política pública (como por exemplo recursos organizacionais indisponíveis), que vão requerer do agente uma ação imediata para que seja possível atender o cidadão. Conforme observou Matland (1995), fatores relacionados ao contexto da implementação podem suplantar as regras que foram criadas no momento da formulação. Nestes casos, a discricionariedade torna-se imprescindível para que a política pública se adéque à 
realidade local, atendendo às necessidades do demandante segundo a ação discricionária do agente (OLIVEIRA, 2012).

Dessa forma, admite-se a importância da discricionariedade para o desenvolvimento das políticas públicas, por outro lado, "o seu exercício permite modificar a política pública à revelia das concepções de seus formuladores e dos grupos que Ihes deram apoio" (LIMA; D'ASCENZI, 2013, p. 105).

Najam (1995) relata que enquanto os estudiosos do modelo top-down acreditavam que a implementação das políticas públicas aconteceria de forma automática, em razão das decisões da classe política, os pesquisadores adeptos do modelo bottom-up buscavam desafiar essa suposição através de estudos de casos detalhados que mostravam que a implementação não se tratava de um mero processo administrativo. Nesse contexto, Najam (1995) relata o surgimento de estudiosos preocupados em compreender como de fato é a implementação, rompendo com as proposições normativas dos modelos top-down e botton-up, desenvolvendo novas perspectivas analíticas.

Najam (1995) acredita que o fato da implementação de uma política pública não ser efetivada não significa que a ação para implementá-la não tenha ocorrido, mas simplesmente que a implementação não foi alcançada. As possíveis causas para isso seriam: as etapas prescritas não terem sido alcançadas; as regras para alcançar os objetivos não terem sido seguidas; ou terem sido seguidas, mas não foram capazes de alcançar os resultados previstos; a possibilidade dos objetivos terem sido transformados; ou até mesmo ter ocorrido a combinação desses fatores mencionados. Najam (1995, p.33) argumenta, portanto, que a implementação é um processo dinâmico, e "que não se limita a traduzir uma política declarada em ação, podendo transformar a própria política". 0 autor defende ainda que a implementação é um processo complexo que ocorre por meio da interação de vários atores localizados em diferentes níveis, dentro e fora do governo.

Nessa perspectiva, Najam (1995) desenvolve o The 5C Protocol, mais conhecido na literatura nacional como a Matriz dos 5Cs (ZANI; COSTA, 2014). A Matriz dos 5Cs consiste em um conjunto de cinco variáveis críticas, interligadas com o objetivo de "identificar grupos-chaves de variáveis explicativas que permitam uma melhor compreensão da implementação" (NAJAM, 1995, p. 30). Essa matriz apresenta cinco variáveis interconectadas, as quais podem ser traduzidas como (1) conteúdo, (2) contexto, (3) compromisso, (4) capacidade, e (5) clientes e coalizões. 
Figura 1 - Matriz 5C

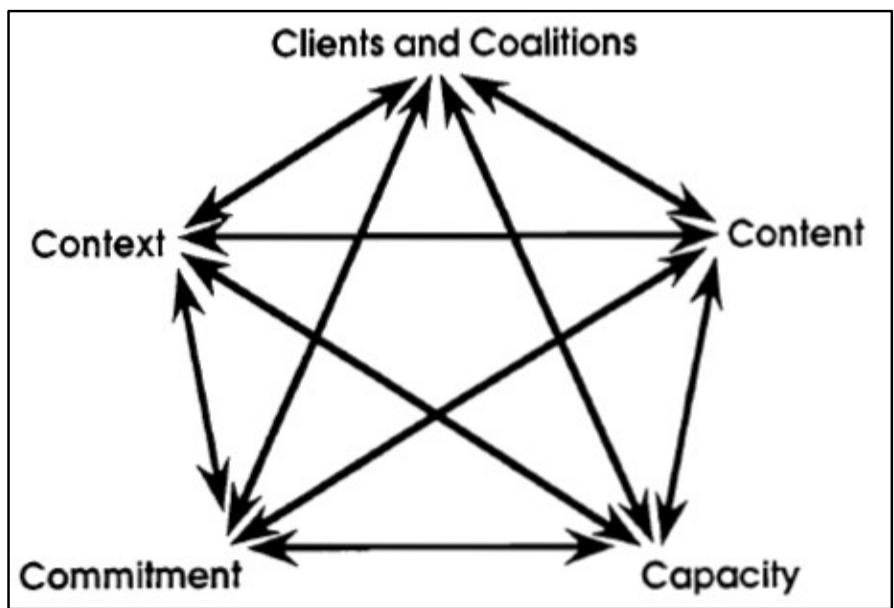

Fonte: NAJAM, 1995.

Najam (1995) defende que as variáveis mencionadas são influenciadas umas pelas outras, embora esta influência possa variar de acordo com cada política específica. Isto significa que a variável conteúdo, por exemplo, é capaz de influenciar e ser influenciada pelas outras quatro variáveis. É possível ainda que o conteúdo da política, na prática, não seja alcançado ou seja alterado, em razão da falta de compromisso do implementador, de pressões de clientes e coalizões, da incapacidade administrativa, e de um contexto inapropriado.

A variável conteúdo, segundo Najam (1995), refere-se especificamente aos objetivos da política e como é problematizada sua questão central (teoria causal). Refere-se ainda ao design da política, suas estratégias para que ela seja alcançada, sua tipologia, bem como seus poderes remuneratórios, normativos ou coercitivos; ou seja, abarca de uma forma geral o conteúdo da política. Najam (1995) adverte, contudo, que a influência das demais variáveis podem interferir no conteúdo efetivo da política, podendo torná-la diferente da política prescrita.

A variável contexto compreende aspectos sociais, econômicos, políticos e legais, desde que diretamente relacionados ao contexto institucional em que a política é executada, a fim de que não se busque compreender aspectos que não possam interferir na implementação da política. Esta variável contempla ainda os aspectos burocráticos, institucionais e relações entre agências. Em resumo, esta variável foca o ambiente institucional.

A variável compromisso é uma variável que pode ser vista sob a perspectiva bottom-up ou top-down. Isto se dá porque aqueles que utilizam a proposta analítica do modelo bottom-up defendem que o compromisso por parte dos implementadores da política depende dos aspectos institucionais e do comportamento dos beneficiários/usuários da política. Neste caso, a discricionariedade do agente implementador seria um fator presente e relevante. Por outro lado, aqueles que se identificam com 0 
modelo top-down defendem que as variáveis conteúdo e capacidade são capazes de exercer forte influência na variável compromisso, fazendo com que esta última seja controlada pelo topo, ou seja, pelos responsáveis pela formulação da política. Najam (1995) defende a ideia de que é necessário que haja disposição e compromisso não somente no nível de rua, mas em todos os níveis, como nos intermediários e políticos (formuladores).

No que se refere à variável capacidade, o autor relata que há grande consenso na literatura quanto ao seu significado. Trata-se basicamente da capacidade administrativa, humana e financeira para a implementação da política. Contudo, o autor adverte que disponibilizar recursos não é assunto simples. Saber exatamente quais são os recursos necessários muitas vezes é o grande desafio. Desta forma, é preciso identificar os recursos adequados à implementação da política e em seguida alocá-los eficientemente. Segundo Najam (1995), esta variável contempla ainda a incapacidade de implementar a política em função de excesso de trabalho, funcionários mal treinados, falta de informações e recursos financeiros e tecnológicos insuficientes.

Por fim, a variável clientes e coalizões refere-se aos grupos-alvo, aqueles a quem a política é entregue. Diferentemente das variáveis anteriores, que dão enfoque aos governos e às burocracias, esta variável trata dos beneficiários e das coalizões de interesse que podem impactar a política pública. Estes beneficiários e coalizões devem ser identificados e suas forças mapeadas para compreender sua influência nas demais variáveis.

Najam (1995) sugere que a Matriz 5Cs é uma ferramenta para compreender as complexidades e as mudanças ocorridas nas políticas públicas durante sua implementação, e lembra que, em função da particularidade de cada política pública, "algumas variáveis serão provavelmente mais manifestas e complexas em algumas situações do que em outras" (NAJAM, 1995, p. 55).

\section{METODOLOGIA DA PESQUISA}

Para analisar os desafios existentes na implementação da política de compras públicas sustentáveis no CEFET/ RJ, recorreu-se ao método de estudo de caso, que segundo Yin (2015) consiste em uma pesquisa empírica com vistas a compreender em profundidade um fenômeno contemporâneo em seu contexto. Por tratar-se de pesquisa qualitativa, foram utilizadas, como principais fontes de coleta de dados, entrevistas semiestruturadas e pesquisa documental.

Para Yin (2015) a entrevista é uma das fontes mais importantes de informação na realização de um estudo de caso. Elas permitem ao pesquisador coletar indícios dos modos como cada um dos sujeitos percebe e significa sua realidade, levantando informações consistentes que lhe 
permitam descrever e compreender a lógica que se estabelece no interior de determinado grupo (DUARTE, 2004). Quanto à pesquisa documental, Yin (2015) defende seu uso como importante instrumento para corroborar e aumentar as evidências oriundas das entrevistas, observação e dados.

Nesse sentido, foram realizadas 10 entrevistas com funcionários da organização responsáveis pela especificação de materiais, bens e serviços, bem como funcionários lotados nos setores de compras, fiscais de contratos e gestores, entre os meses de maio e setembro de 2018. As entrevistas foram realizadas tendo como base um roteiro semiestruturado previamente elaborado, tendo em vista o referencial teórico utilizado (Matriz $5 \mathrm{Cs}$ ) e a literatura sobre compras sustentáveis. Em seguida essas entrevistas foram transcritas e analisadas.

De forma complementar, foram levantados documentos institucionais capazes de indicar de que forma as compras sustentáveis são conduzidas pela organização. Assim, foram utilizados como fonte documental os Planos de Desenvolvimento Institucional (PDI) (2010-2014 e 2015-2019), Relatórios de Gestão (2010 a 2017), Planos Anuais de Capacitação (2010 a 2018), Editais de Licitação (2015 a 2018), Plano de Gestão de Logística Sustentável (2018) e formulários para abertura de processo de compras (2018).

Para análise dos dados foi utilizado o método de combinações de padrões que, segundo Yin (2015), consiste na comparação e combinação entre padrões identificados antes da coleta de dados e padrões provenientes das descobertas empíricas. Esse método, com o auxílio de matriz de categorias analíticas, é capaz de evidenciar os dados encontrados em campo pelo pesquisador (YIN, 2015).

A categorização e análise de dados foram baseadas na Matriz 5C (NAJAM, 1995), por meio da qual foi possível compreender de que maneira as variáveis conteúdo, capacidade, contexto, compromisso e clientes e coalizões interferem na implementação da política de compras públicas sustentáveis da instituição analisada.

\section{ANÁLISE DOS RESULTADOS}

\subsection{Variável Conteúdo}

O Ministério do Meio Ambiente (2009) classifica as compras sustentáveis como aquisições de produtos e serviços que considerem em todos os seus processos aspectos ambiental, social e econômico. O Decreto $n^{0} 7.746 / 2012$, recentemente alterado pelo Decreto $n^{0}$ 9.178/2017, estabelece que os critérios de sustentabilidade devem ser exigidos nos editais de licitação por meio das especificações técnicas do objeto, das cláusulas que estabelecem as obrigações da contratada ou 
como requisito de habilitação das empresas que pretendem participar das licitações públicas. 0 estabelecimento dos critérios de sustentabilidade é derivado do artigo $3^{\circ}$ da Lei de Licitações, que estabelece que "a licitação destina-se a garantir a observância do princípio constitucional da isonomia, a seleção da proposta mais vantajosa para a administração e a promoção do desenvolvimento nacional sustentável" (BRASIL, 1993). No entanto, apesar da existência do arcabouço jurídico referente às compras sustentáveis, muitas vezes esta política não se concretiza, conforme constatado em relatório do TCU (2018), já apontado inicialmente.

Najam (1995) afirma que as relações entre as variáveis apresentadas em sua teoria podem fazer com que o conteúdo da "política em ação" seja significativamente diferente da política originalmente definida. Desta forma, buscou-se verificar nesta pesquisa, por meio da variável conteúdo, se as compras sustentáveis são implementadas na instituição analisada, como estão previstas originalmente em seu conteúdo normativo.

Nos documentos institucionais da organização analisada, poucas foram as referências relacionadas à política de compras sustentáveis. $O$ que se verificou foi a implementação da política de gestão de resíduos sólidos. Em seu último relatório (2016), como resultado do programa de coleta seletiva, a instituição informou que destinou para reciclagem aproximadamente 3,5 toneladas de materiais entre setembro de 2015 e setembro de 2016.

Apesar da implementação da política de gestão de resíduos sólidos, e de tal política estar relacionada ao aspecto da sustentabilidade, foi possível verificar poucas compras sustentáveis. Dentre elas, destacam-se a aquisição de lâmpadas led e as compras relacionadas à gestão de resíduos sólidos, como a contratação de empresa para a coleta de lâmpadas descartadas e a aquisição de coletores de lixo para o programa de Coleta Seletiva. Tais compras inclusive foram apontadas por alguns funcionários quando questionados sobre quais compras sustentáveis foram realizadas pela instituição.

O CEFET hoje está começando a trocar as suas lâmpadas fluorescentes por lâmpadas de led. Então eu acho que existe aí também uma possibilidade, um conhecimento também do servidor com relação também a parte de eficiência energética, com relação a redução de consumo. (Entrevistado 3 - Gestor)

A gente comprou lixeiras para separar o que é item reciclável e orgânico. (Entrevistado 8 Comprador)

No entanto, a maioria dos funcionários que trabalham solicitando materiais, bens e serviços, e até mesmo funcionários que trabalham diretamente nos setores de compras, alegaram não ter conhecimento sobre a realização de compras sustentáveis na instituição ou declararam que tal política ainda é muito incipiente no órgão. 
Nem sei. O CEFET ele tem uma política? Tu sabe dizer se ele tem alguma política [de compras sustentáveis]? (Entrevistado 1 - Solicitante e Fiscal de Contrato)

Ainda não tive conhecimento ainda de nenhuma aquisição sustentável pelo CEFET. (Entrevistado 2 - Comprador)

A compra sustentável pra gente ela é bem, no nosso âmbito aqui no CEFET, ela é bem fraca. (Entrevistado 7 - Comprador)

Verificou-se, ainda, que as planilhas eletrônicas para abertura dos processos de compras possuem uma observação para que os solicitantes se atentem à necessidade de seguir as legislações que tratam das compras sustentáveis. Mas, de modo geral, os documentos analisados, bem como os relatos dos entrevistados, apontam que apesar do conteúdo da política prever a obrigatoriedade de inclusão de critérios sustentáveis nas compras públicas, a organização ainda precisa avançar na inserção de critérios de sustentabilidade na especificação de materiais, bens e serviços, pois tal iniciativa ainda é muito incipiente.

\subsection{Variável Capacidade}

Segundo Najam (1995), a importância desta variável é unanimemente reconhecida pela literatura de políticas públicas. A necessidade de capacidade das agências e de agentes responsáveis pela implementação de políticas públicas é fundamental para que determinada política seja implementada tal qual foi formulada. Nesse sentido, foi possível identificar durante a pesquisa pouco conhecimento por parte de trabalhadores a respeito do conteúdo da política de compras sustentáveis, como pode ser observado no relato de um funcionário responsável pelas especificações de materiais, bens e serviços de uma das unidades do CEFET/RJ.

Eu não trabalho com compras, fico mais na área de solicitante, não tenho muito conhecimento dessa política. [...] É porque eu não tô envolvido com compras, né? Então eu não tenho muito conhecimento [de compras sustentáveis]. (Entrevistado 1 - Solicitante e Fiscal de Contrato)

Vale ressaltar, contudo, que a IN n 01/2010 do MPOG (Ministério do Planejamento, Orçamento e Gestão) estabelece que as especificações para a aquisição de bens, contratação de serviços e obras devem conter critérios de sustentabilidade ambiental, considerando os processos de extração ou fabricação, utilização e descarte dos produtos e matérias-primas. Semelhantemente, o Decreto $n^{0} 7.746 / 2012$, alterado pelo Decreto $n^{0} 9.178 / 2017$, regulamenta que uma das maneiras de inserção de critérios e práticas de sustentabilidade se dá por meio da especificação técnica do objeto, revelando, assim, a importância dos funcionários solicitantes de materiais, bens e serviços como agentes fundamentais na implementação da política das compras sustentáveis. 
Nesse sentido, grande parte dos entrevistados que trabalham nos setores de compras alegou ser fundamental que os funcionários responsáveis pelas especificações dos materiais, bens e serviços tenham capacitação e, consequentemente, conhecimento do conteúdo da política de compras públicas sustentáveis.

[...] tem vários atores aqui, a gente não vai ter tempo pra falar de tudo isso, tanto daquele que enxergou uma necessidade, quem sabe um professor lá que tá no seu laboratório que precisa comprar lá o item x. Então será que ele tem essa capacitação? [...] Fez algum curso que o qualificou pra lidar com esses critérios [de sustentabilidade]? (Entrevistado 5 - Gestor)

Com a finalidade de verificar como a instituição está capacitando seus funcionários quanto ao tema, buscou-se analisar os Planos Anuais de Capacitação do CEFET/RJ entre os anos de $2010 \mathrm{e}$ 2018. Verificou-se que apenas no ano de 2016 houve uma capacitação específica sobre compras públicas sustentáveis. No entanto, segundo relato de um dos gestores da instituição, o curso não foi destinado aos funcionários responsáveis pelas especificações de materiais, bens e serviços, mas apenas aos trabalhadores que atuavam nos setores de compras.

Nós tivemos aí algumas capacitações, só que essas capacitações elas foram diretamente ligadas a quem trabalha com compras. [...] Eu acho que nós tivemos uma aí [uma capacitação] em 2014, feito pelo pessoal do Jardim Botânico, né? Estávamos juntos. Mas eu lembro que eram só pessoas que estavam ligadas diretamente [com compras]. (Entrevistado 3 - Gestor)

Apesar do baixo número de cursos sobre o tema empreendidos pela instituição, foi possível identificar em muitos editais de licitação da instituição cláusulas contratuais que obrigam as empresas a adotar boas práticas de sustentabilidade, como racionalização do uso de substâncias tóxicas e poluentes, substituição de substâncias tóxicas por outras atóxicas ou de menor toxicidade, economia no consumo de energia e água, destinação adequada dos resíduos gerados nas atividades de limpeza, asseio e conservação, dentre outras. Assim, a importância da capacitação de fiscais de contrato também foi destacada como relevante pelos entrevistados.

Quando esse material ou serviço ele é executado ou entregue aqui na unidade, o gestor do contrato, que eu acho que é aí o ponto, o gestor do contrato ele têm ciência, dá atenção, vai conseguir observar no decorrer do contrato se esses critérios foram ou não atendidos? Então eu acho que a capacitação tem ficado muito na formulação do edital. Alcança pouco quem concebe a necessidade, e em última análise, quem recebe e gerencia 0 contrato. (Entrevistado 5 - Gestor)

Então assim, pra ser sincero, concluir [o contrato de obra] às vezes é o maior desafio. Então a gente acaba, numa ordem de prioridades, a gente, poxa, se o cara não tá nem fazendo 0 serviço, quem dirá separando os materiais em categorias diferentes? (Entrevistado 4 Solicitante e Fiscal de Contrato)

Em resumo, foi possível identificar que a baixa capacidade institucional na implementação da política de compras sustentáveis compromete a efetiva implementação da política na organização. 
A identificação dos níveis de necessidades de capacitação, bem como a efetiva capacitação dos agentes implementadores é, segundo Najam (1995), indispensável para a implementação de qualquer política pública. Desta forma, conclui-se que a necessidade de capacitação do corpo técnico do CEFET/RJ, como solicitantes, fiscais de contrato, funcionários lotados nos setores de compras e gestores, é fundamental para que as compras sustentáveis sejam efetivas na organização da forma como é preconizada em todo seu conjunto legal e normativo.

\subsection{Variável Contexto}

Nesta pesquisa, alguns pontos relacionados ao contexto da política de compras públicas sustentáveis emergiram durante a coleta e análise de dados: a participação dos órgãos de fiscalização e controle, e o mercado fornecedor.

Grande parte dos entrevistados reconheceu ser importante a participação dos órgãos de fiscalização e controle para que a política de compras públicas sustentáveis seja implementada.

Eu acho que a sustentabilidade está num processo de otimização. É bom quando vem um órgão de fora, um negócio assim e bate o martelo e: "Olha, eu quero desse jeito e pronto!" Aí a gente dá até um empurrãozinho pra frente. (Entrevistado 4 - Solicitante e Fiscal de Contrato)

No entanto, alguns entrevistados acreditam que esses órgãos geralmente preocupam-se mais com outras questões (como a economicidade das compras públicas) do que efetivamente com aquelas relacionadas à sustentabilidade. Esse posicionamento pode ser claramente identificado ao analisar o relato de um experiente funcionário da instituição:

\footnotetext{
Olha, eu vou ser bem sincero, eu costumo assim, eu recebo, tipo um periódico, algumas atualizações do TCU no meu e-mail, e eu dificilmente vejo alguma jurisprudência nesse sentido da sustentabilidade. Acredito que exista, mas não é comum entendeu. $E$ sinceramente não é algo, que ainda que seja cobrado, para mim não é algo que seja cobrado com tanta ênfase como em outras coisas, entendeu. Às vezes eles batem muito na tecla da economicidade, da legalidade, de outros princípios, mas a questão da sustentabilidade eu não vejo assim os órgãos de controle tratando com ênfase. Não vejo. (Entrevistado 8 Comprador)
}

A relevância da participação dos órgãos de fiscalização e controle na implementação da política de compras sustentáveis está em consonância com o que Najam (1995) denomina de relação entre agências. Essas agências, que podem ser caracterizadas como agências de cooperação, competição, conluio, ou coerção, precisam ser identificadas, ter suas dinâmicas e interesses compreendidos, além de suas relações com a agência principal analisadas. Isso porque o desempenho de qualquer agência implementadora de política pública é significativamente impactado por essas relações. Desta maneira, sabe-se que os órgãos de fiscalização e controle, que nitidamente assumem 
papel de coerção nessa relação, estão buscando fazer valer as legislações de compras sustentáveis, ainda que muitas vezes adotando medidas pedagógicas e recomendações ${ }^{2}$. Entretanto, pelo fato de não haver notificações diretas ao órgão, há baixa efetividade da implementação da política pública de compras sustentáveis.

Verificou-se ainda que a maioria dos entrevistados acreditam que o mercado fornecedor de materiais, bens e serviços com características sustentáveis ainda se encontra prematuro, e que em alguma medida isso interfere nas compras sustentáveis.

O mercado acaba sendo mais reduzido, né? A oferta acaba sendo mais reduzida porque as empresas precisam de certificação, e tudo mais. (Entrevistado 1 - Solicitante e Fiscal de Contrato)

Como desdobramento da percepção de escassez de fornecedores, parte dos entrevistados destacaram ser possível que o preço de materiais, bens e serviços com características sustentáveis sejam mais caros. Entretanto, relataram que tal preço se justificaria, visto que os ganhos sociais e ambientais estariam sendo considerados nessas aquisições.

Então esse pagar caro, às vezes a linguagem cara, pode muito estar se atendo ao caráter econômico, mas não é caro social e não é caro ambientalmente dizendo. [...] Então, quando você pega esse caro e dilui ele nos critérios sociais, ambientais e econômicos, você vê que não tem nada de caro aí, pelo contrário. (Entrevistado 5 - Gestor)

Apesar dos relatos referentes à incipiência do mercado fornecedor e a possibilidade de preços mais elevados em função das características sustentáveis de materiais, bens e serviços, não houve apontamentos de que tais fatores poderiam interferir de forma significativa na implementação da política de compras sustentáveis na instituição.

\subsection{Variável Compromisso}

Para que as políticas públicas sejam efetivamente implementadas é fundamental que haja compromisso em todos os níveis organizacionais pelos quais ela passa, isto inclui os níveis políticos, intermediários e agentes implementadores (NAJAM, 1995). Esta perspectiva vai além da polarização analítica existente entre as perspectivas top-down e bottom-up já apresentadas anteriormente.

Najam (1995) defende que a política pública que surge em função de uma conveniência política, e não em função de um efetivo compromisso com a solução de um problema público, tende a não ser implementada por descomprometimento do topo. Ao mesmo tempo se os burocratas - que se encontram na ponta e geralmente gozam de alto nível de discricionariedade - não estiverem comprometidos, frustrarão a política ou entregarão uma política divergente da formulada. É importante 
considerar, ainda, a relevância dos níveis intermediários, responsáveis em fazer com que a vontade política seja desdobrada e transformada em vontade dos implementadores de nível de rua.

Sem desconsiderar a importância de analisar o compromisso dos formuladores da política pública, este trabalho focou o compromisso do CEFET/RJ, bem como de seus trabalhadores na implementação das compras públicas sustentáveis.

A política de gestão de resíduos sólidos guarda forte relação com a política de compras sustentáveis, visto que ambas as políticas estão contidas na Instrução Normativa n 10/2012 do MPOG (Ministério do Planejamento, Orçamento e Gestão), que estabelece regras para elaboração dos Planos de Gestão de Logística Sustentável, e da A3P (Agenda Ambiental na Administração Pública). Contudo, sob o ponto de vista organizacional, o que se percebe é um maior comprometimento do CEFET/ RJ com a política de resíduos sólidos do que com as compras sustentáveis. Isso porque a política de gestão de resíduos sólidos possui destaque no planejamento organizacional e nos relatórios de gestão, diferentemente da política de compras sustentáveis. Esta percepção construída por meio de análise documental é fortalecida pelo relato de alguns entrevistados.

\footnotetext{
Então, no CEFET, assim, essa questão [compras sustentáveis] é bem tímida mesmo. Algo assim mais forte que a gente viu hoje no CEFET dessa questão de sustentabilidade eu diria que nem acaba envolvendo diretamente licitações, mas existe uma comissão hoje no CEFET que é a Comissão de Coleta Seletiva Solidária, que a comissão Central pertence ao Maracanã (Entrevistado 8 - Comprador)

Basta ter uma vontade da administração do CEFET em começar esse processo, começar essas contratações [sustentáveis], pelo menos no que couber, de materiais que sejam realizados de forma sustentável. (Entrevistado 2 - Comprador)
}

Como já mencionado, os formulários para solicitação de materiais, bens e serviços possuem indicação para que os solicitantes observem as legislações que tratam das compras sustentáveis. No entanto, a falta de mecanismos institucionais de gestão e controle que obriguem que tal medida seja respeitada, faz com que as compras públicas caiam na discricionariedade dos solicitantes.

Ainda no que se refere à discricionariedade dos funcionários na implementação da política de compras sustentáveis na instituição, foi possível verificar que em alguns pregões eletrônicos houve pregoeiros que exigiram que empresas licitantes vencedoras encaminhassem Declaração de Sustentabilidade ${ }^{3}$, enquanto outros adjudicaram itens sem que as empresas encaminhassem tal declaração (apesar dos editais de licitação assim exigirem). Esta constatação reforça a ideia de que o documento exigido não garante a compra sustentável, especialmente se houver falta de compromisso ou capacidade por parte do pregoeiro. 
Durante as entrevistas não houve quem discordasse da importância das compras públicas sustentáveis. Da mesma forma, verificou-se que os documentos institucionais reconhecem a relevância da sustentabilidade. Contudo, é importante ampliar o comprometimento com a política de compras sustentáveis na alta administração do CEFET/ RJ, incluindo essa temática entre os objetivos estratégicos, metas e indicadores de performance da instituição.

No entanto, como já mencionado, o compromisso com a política precisa estar difundido pela organização, sendo também fundamental que os funcionários de baixo escalão estejam conscientes e capacitados para implementar as compras públicas sustentáveis. Inclusive, parte dos entrevistados acreditou que essa medida é indispensável para que a política seja implementada.

\footnotetext{
Acredito que o trabalho hoje da gente implementar isso de uma forma legal aqui no CEFET seria um trabalho de conscientização dos servidores, entendeu. Eu acho que esse seria 0 principal assim para mudar o pensamento das pessoas, alertar sobre importância disso. Eu acredito que a partir do momento que as pessoas, servidores, estiverem engajados, entenderem realmente necessidade de mudar o pensamento, mudar a cultura, implementar vai ser muito fácil. (Entrevistado 8 - Comprador)
}

Com a adesão voluntária e oficial à A3P4 no dia 26/01/2018, verifica-se a oportunidade para que o CEFET/RJ promova a sensibilização e capacitação de seus funcionários, visto que tais ações correspondem a um dos eixos temáticos do programa. Espera-se que com tais iniciativas seja possível que a organização aumente o nível de compromisso de seus funcionários com a política de compras pública sustentáveis.

\subsection{Variável Clientes e Coalizões}

Diferentemente das demais variáveis, que se concentram especialmente na análise de aspectos políticos e burocráticos, esta variável tem seu foco analítico em atores não estatais, com destaque para os beneficiários da política pública e coalizões de grupos de interesse. Por meio de seu poder de influência, esses atores podem ser capazes de acelerar, desacelerar, redirecionar ou até mesmo parar o processo de implementação de determinada política pública (NAJAM, 1995).

Nesse sentido, buscou-se verificar junto aos trabalhadores do CEFET/RJ em que medidas atores não ligados ao Estado influenciam a implementação da política de compras sustentáveis. Foi possível verificar que esta variável, na opinião dos entrevistados, é a que menos exerce influência, a favor ou contra, na implementação da política.

De modo geral, os entrevistados relataram que percebem a sociedade cada vez mais fiscalizadora das atividades públicas, especialmente em função do mau uso de recursos públicos. № 
entanto, especificamente no que se refere à fiscalização da sociedade sobre a política de compras sustentáveis, os entrevistados relataram não perceberem qualquer interferência:

Tô imaginando que a sua pergunta vai nessa direção, ou seja: "tem órgãos públicos na minha cidade? Com quem eles contratam? Como eles têm as suas demandas? Quem tá lá recebendo esse material?" A sociedade não tem essa plena concepção. Na minha análise, não tem essa concepção. Acho que vai demorar algum tempo ainda pra que a sociedade, falando aqui de modo genérico, absorva esse papel que ela tem. (Entrevistado 5 - Gestor)

No que se refere à variável clientes e coalizões, deve ser considerado que a política de compras públicas sustentáveis é implementada por burocratas que não se encontram em nível de rua. Quanto a isto, literatura aponta que os burocratas de nível de rua são funcionários responsáveis pela implementação da política e que estão diretamente em contato com seus beneficiários, como por exemplo, os agentes de saúde, segurança e educação, que constantemente se encontram em contato com o cidadão. Tais agentes são constantemente pressionados pelos beneficiários, suas demandas e cobranças, e tal relação é capaz de interferir na implementação da política. Já os burocratas responsáveis pela implementação da política de compraa sustentáveis, apesar de estarem na ponta do processo de implementação, possuem pouca relação com os beneficiários da política e, por não estarem a nível de rua, encontram-se menos suscetíveis às pressões advindas do público alvo.

\section{CONCLUSÕES}

Este artigo teve como objetivo analisar a implementação da política de compras públicas sustentáveis no CEFET/RJ a partir do referencial teórico e analítico fornecido pela Matriz de $5 \mathrm{Cs}$ (NAJAM, 1995). Com a pesquisa realizada foi possível verificar fortes influências das variáveis capacidade e compromisso na implementação da referida política pública, em comparação com as demais variáveis descritas no modelo.

A falta de capacitação de funcionários, responsáveis pela inserção de critérios de sustentabilidade nas especificações materiais, bens e serviços, faz com que a política pública não seja implementada como deveria. Já os funcionários responsáveis pela condução do processo de compras, que conhecem um pouco mais da política pública, dizem não possuir autonomia para alteração das especificações dos materiais solicitados, cabendo apenas prosseguir com os processos de compras. Além do mais, verificou-se ausência de capacitação de funcionários responsáveis pelas fiscalizações de contratos, visto que estes são agentes capazes de fazer valer junto às empresas e prestadores de serviços as cláusulas contratuais estabelecidas em edital referente às obrigações quanto às boas 
práticas de sustentabilidade. Esta ausência de capacitação reflete, em última análise, pouca capacidade institucional para a implementação da referida política.

No que se refere à variável compromisso, foi possível verificar comprometimento institucional com questões relacionadas à sustentabilidade, especialmente no que se refere à política de gestão de resíduos sólidos. No entanto, não foi identificado o mesmo nível de compromisso com as compras sustentáveis. Quanto a isso, vale destacar a importância do comprometimento da alta gestão com a criação de objetivos, metas e indicadores de avaliação da política de compras sustentável, de modo que sua implementação não fique totalmente na discricionariedade dos agentes implementadores encontrados na linha de frente. Em se tratando especificamente do compromisso individual dos trabalhadores, o que se constatou foi opinião unânime quanto à importância da política. No entanto, em algumas licitações as declarações de sustentabilidade não foram exigidas, apontando 0 caráter meramente formal do documento e a pouca relevância atribuída a ele por parte de alguns pregoeiros.

As interações das variáveis aqui apresentadas são capazes de apontar para algumas medidas necessárias a serem tomadas pelo topo (formuladores da política) e pela alta administração dos órgãos públicos. Referente aos formuladores da política, é importante que estes promovam as legislações que tratam das compras sustentáveis na Administração Pública e fortaleçam os órgãos de fiscalização e controle. Já no que se refere às medidas da alta administração dos órgãos públicos, é importante que gestores estabeleçam políticas institucionais que insiram as compras sustentáveis em seus planejamentos estratégicos, desenvolvam cultura organizacional e capacitações no tocante ao tema, e criem mecanismos de avaliação e controle com vistas à eficácia da implementação da política de compras públicas sustentáveis.

\section{REFERÊNCIAS}

BRASIL. Lei n 8.666, de 21 de junho de 1993. Regulamenta o art. 37, inciso XXI, da Constituição Federal, institui normas para licitações e contratos da Administração Pública e dá outras providências. Disponível em: http://www.planalto.gov.br/ccivil_03/leis/L8666 cons.htm. Acesso em: 28 maio 2018.

DUARTE, R. Entrevistas em pesquisa qualitativa. Revista Educar em Magazine, Curitiba, v.4, n. 24, p. 213-225, 2004.

EISENHARDT, K.M. Agency Theory: An Assessment and Review. The Academy of Management Review, n.14, v.1, p. 57-74, 1989.

FARIA, C. A. (org). Implementação de Políticas Públicas. Teoria e Prática. Belo Horizonte: Editora PUCMINAS, 2012. 
FREY, K. Políticas públicas: um debate conceitual e reflexões referentes à prática da análise de políticas públicas no Brasil. Planejamento e Políticas Públicas (IPEA), Brasília, v. 21, p. 211-259, 2000.

HOWLETT, M; RAMESH, M; PERL, A. Política Pública: seus ciclos e subsistemas: uma abordagem integral. Rio de Janeiro: Elsevier, 2013

LIMA, L; D'ASCENZI, L. Implementação de políticas públicas: perspectivas analíticas. Revista de Sociologia e Política, [S.I.], v. 21, n. 48, p. 101-110, dez. 2013.

LIPSKY, M. Street-Level Bureaucracy: Dilemmas of the individual in public services. New York: Russel Sage, 1980.

LOTTA, G. O papel das burocracias do nível da rua na implementação de políticas públicas: entre 0 controle e a discricionariedade. In: FARIA, C. A (org). Implementação de Políticas Públicas. Teoria e Prática. Belo Horizonte: Editora: PUCMINAS, 2012.

MATLAND, R. E. Synthesizing the Implementation Literature: The ambiguity-conflict model of policy implementation. Journal of Public Administration Research and Theory, Oxford, v. 2, n. 5, p. 145174, Apr, 1995.

MMA. Agenda Ambiental na Administração Pública (A3P). Cartilha da Secretaria de Articulação Institucional e Cidadania Ambiental. Departamento de Cidadania e Responsabilidade Socioambiental. Brasília - DF, 5 ed. rev. atual., 2009.

NAJAM, A. Learning from the literature on policy implementation: a synthesis perspective. Luxemburgo: International Institute for Applied Systems Analysis, 1995.

NEPP. Modelo de avaliação de programas sociais prioritários: relatório final. Campinas, 1999. Disponível em https://www.nepp.unicamp.br/upload/documents/publicacoes/24a44e 81531bb06d29615e3078ca4de0.pdf Acesso em: 18 jan. 2017.

OLIVEIRA, A. Burocratas da linha de frente: executores e fazedores das políticas públicas. Revista de Administração Pública, Rio de Janeiro, v. 46, n. 6, 2012.

ONU. Declaração da Conferência da ONU sobre o Meio Ambiente, 1972. Disponível em: www.mma.gov.br/estruturas/agenda21/_arquivos/estocolmo.doc. Acesso em: 6 jun. 2017.

Nosso Futuro Comum, 1987. Disponível em:

http://www.onu.org.br/rio20/documentos/. Acesso em: 6 jun. 2018.

Declaração do Rio. 1992. Disponível em:

http://www.onu.org.br/rio20/img/2012/01/rio92.pdf. Acesso em: 6 jun. 2018.

RIBEIRO, C; INÁCIO JÚNIOR, E. Mensurando o mercado de compras governamentais brasileiro. Caderno de Finanças Públicas, n. 14, p. 265-287, 2014.

SECCHI, L. Políticas públicas: conceitos, esquemas de análise, casos práticos. 2. ed. São Paulo: Cengage Learning, 2015. 
TCU, Relatório Anual de Atividades: 2017 - Brasília. 2018.

VALENTE, M. A. L. Marco legal das licitações e compras sustentáveis na Administração Pública. Brasília: Biblioteca Digital Câmara, 2011.

YIN, R. K. Estudo de Caso: Planejamento e Métodos. 5 ed. Porto Alegre: Bookman, 2015.

ZANI, F; COSTA, F. Avaliação da implementação do Programa Nacional de Fortalecimento da Agricultura Familiar - novas perspectivas de análise. Rev. Adm. Pública, Rio de Janeiro, v. 48, n. 4, 2014.

\section{Notas}

\footnotetext{
1 Segundo o Relatório de Brundtland, intitulado Our Common Future, desenvolvimento sustentável é "o desenvolvimento que satisfaz as necessidades presentes, sem comprometer a capacidade das gerações futuras de suprir suas próprias necessidades." (ONU, 1987)
}

2 Acórdão TCU n 5804/2013 - 2a Câmara - Recomendação: "[...] ao Órgão que adote critérios de sustentabilidade na aquisição de bens, materiais de tecnologia da informação, bem como na contratação de serviços ou obras"; Acórdão TCU 5937/2013 - 1ª Câmara - Relatório: "[...] adoção parcial de critérios de sustentabilidade ambiental na aquisição de bens e contratação de serviços e obras"; Acórdão TCU no 1056/2017 - Plenário - Acordam: "[...] determinar que, nos termos do art. 45 da Lei $n^{0}$ 8.443, de 1992, o Ministério do Planejamento, Desenvolvimento e Gestão, representado pela Coordenação Geral de Normas de sua Secretaria de Gestão (SEGES/CGNOR) , promova a necessária aplicação do art. $3^{\circ}$, caput, da Lei $n^{0} 8.666$, de 1993 [...]".

$3^{3}$ Os artigos $5^{\circ}$ e $6^{\circ}$ da IN Instrução Normativa n 01, de 19 de janeiro de 2010, do Ministério do Planejamento, Orçamento e Gestão (MPOG) estabelece que os órgãos e entidades da Administração Pública Federal direta, autárquica e fundacional, ao adquirirem bens e contratarem serviços, poderão exigir declaração de atendimento à critérios de sustentabilidade ambiental das empresas fornecedoras.

${ }^{4}$ A A3P (Agenda Ambiental na Administração Pública) é um programa de caráter voluntário cujo objetivo é estimular gestores públicos a introduzir princípios e critérios de sustentabilidade em suas práticas de trabalho, buscando alcançar a economia de recursos naturais e a redução de gastos institucionais por meio de algumas medidas, como o uso racional de bens públicos; a adequada gestão de resíduos; a realização de licitações sustentáveis; a sensibilização e capacitação de funcionários; e da promoção da qualidade de vida no ambiente de trabalho (MMA, 2009). 